\title{
Improved CO Oxidation via Surface Stabilization of Ceria Nanoparticles Induced by Rare-Earth Metal Dopants
}

\author{
Kyung-Jong Noh, ${ }^{\dagger}$ Kyeounghak Kim, ${ }^{\dagger}$ Hyung Jun Kim, ${ }^{\dagger}$ Dongjae Shin, \\ and Jeong Woo Han* \\ Department of Chemical Engineering, Pohang University of Science and Technology \\ (POSTECH), Pohang, Gyeongbuk 37673, Republic of Korea
}

\section{Supporting Information}

\section{Experimental information}

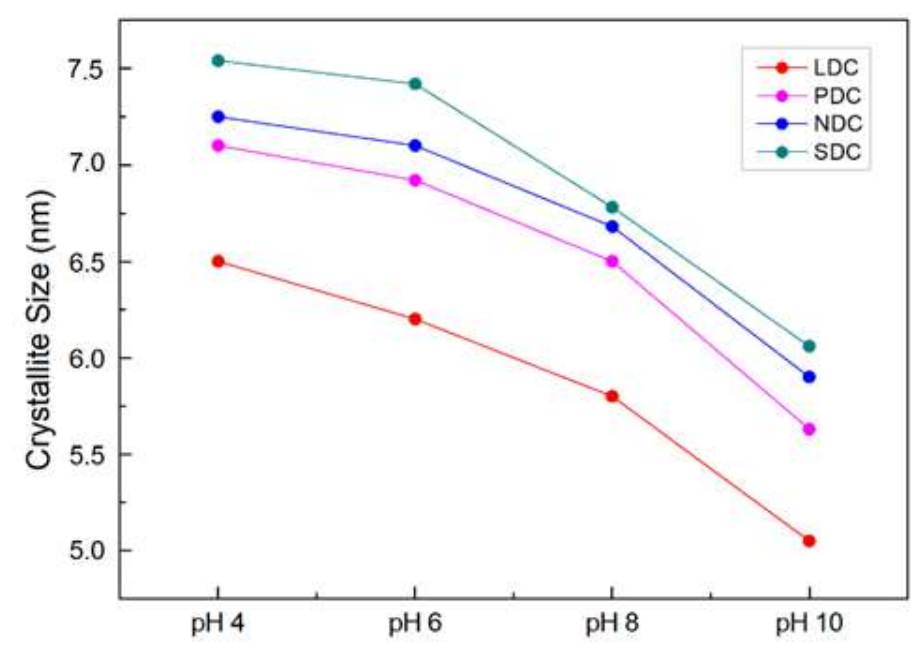

Figure S1: Crystallite size of $\mathrm{Ce}_{0.8} \mathrm{RE}_{0.2} \mathrm{O}_{2}$ as a function of solution $\mathrm{pH}$ (calcined at $500{ }^{\circ} \mathrm{C}$ for 3 hours). 


\begin{tabular}{|c|c|c|c|c|}
\hline & \multicolumn{2}{|c|}{$\mathrm{Ce}_{0.9} \mathrm{RE}_{0.1} \mathrm{O}_{2}(\mathrm{RE}=10 \%)$} & \multicolumn{2}{|c|}{$\mathrm{Ce}_{0.8} \mathrm{RE}_{0.2} \mathrm{O}_{2}(\mathrm{RE}=20 \%)$} \\
\hline & $\mathrm{Ce}(\mathrm{wt} \%)$ & $\mathrm{RE}(\mathrm{wt} \%)$ & $\mathrm{Ce}(\mathrm{wt} \%)$ & $\mathrm{RE}(\mathrm{wt} \%)$ \\
\hline $\mathrm{LDC}$ & 90.44 & 9.56 & 80.67 & 19.33 \\
\hline PDC & 90.67 & 9.33 & 81.33 & 18.67 \\
\hline NDC & 91.39 & 8.61 & 81.16 & 18.84 \\
\hline SDC & 91.33 & 8.67 & 80.92 & 19.08 \\
\hline
\end{tabular}

Table S1: SEM-Energy Dispersive Spectroscopy (EDS) of well-synthesized composites at the same condition (S-REC); (a) $\mathrm{Ce}_{0 .} \mathrm{RE}_{0.1} \mathrm{O}_{2}$ and (b) $\mathrm{Ce}_{0.8} \mathrm{RE}_{0.2} \mathrm{O}_{2}$ nanoparticles.

(a)

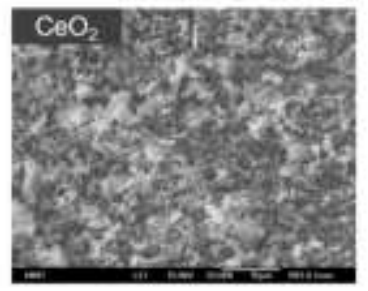

(b)
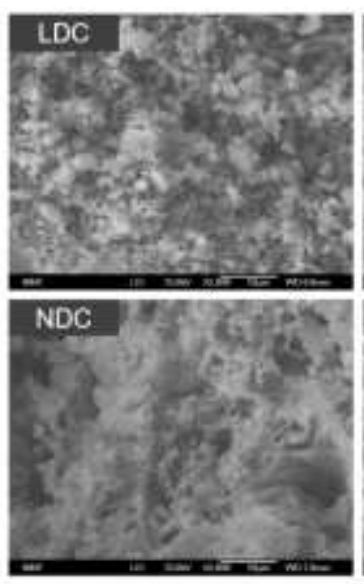
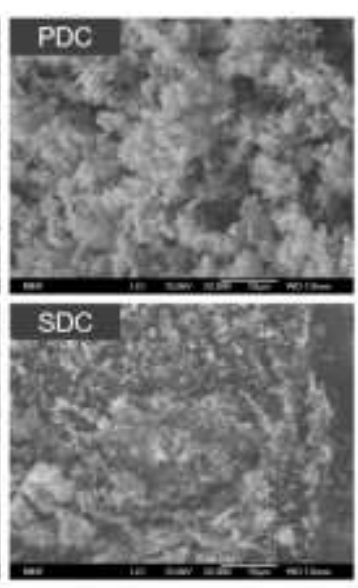

(c)
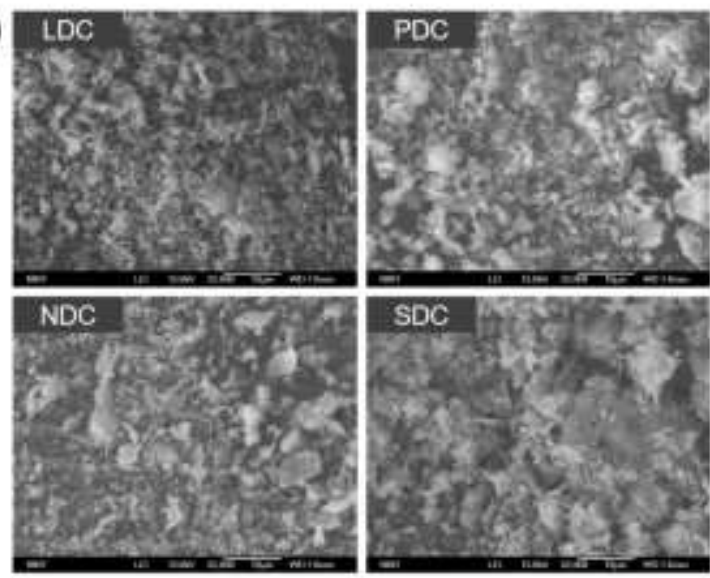

Figure S2: SEM images of well-synthesized composites at the same condition (S-REC); (a) pure $\mathrm{CeO}_{2}$, (b) $\mathrm{Ce}_{0.9} \mathrm{RE}_{0.1} \mathrm{O}_{2}(\mathrm{RE}=10 \%)$, and (c) $\mathrm{Ce}_{0.8} \mathrm{RE}_{0.2} \mathrm{O}_{2}(\mathrm{RE}=20 \%)$ nanoparticles. 

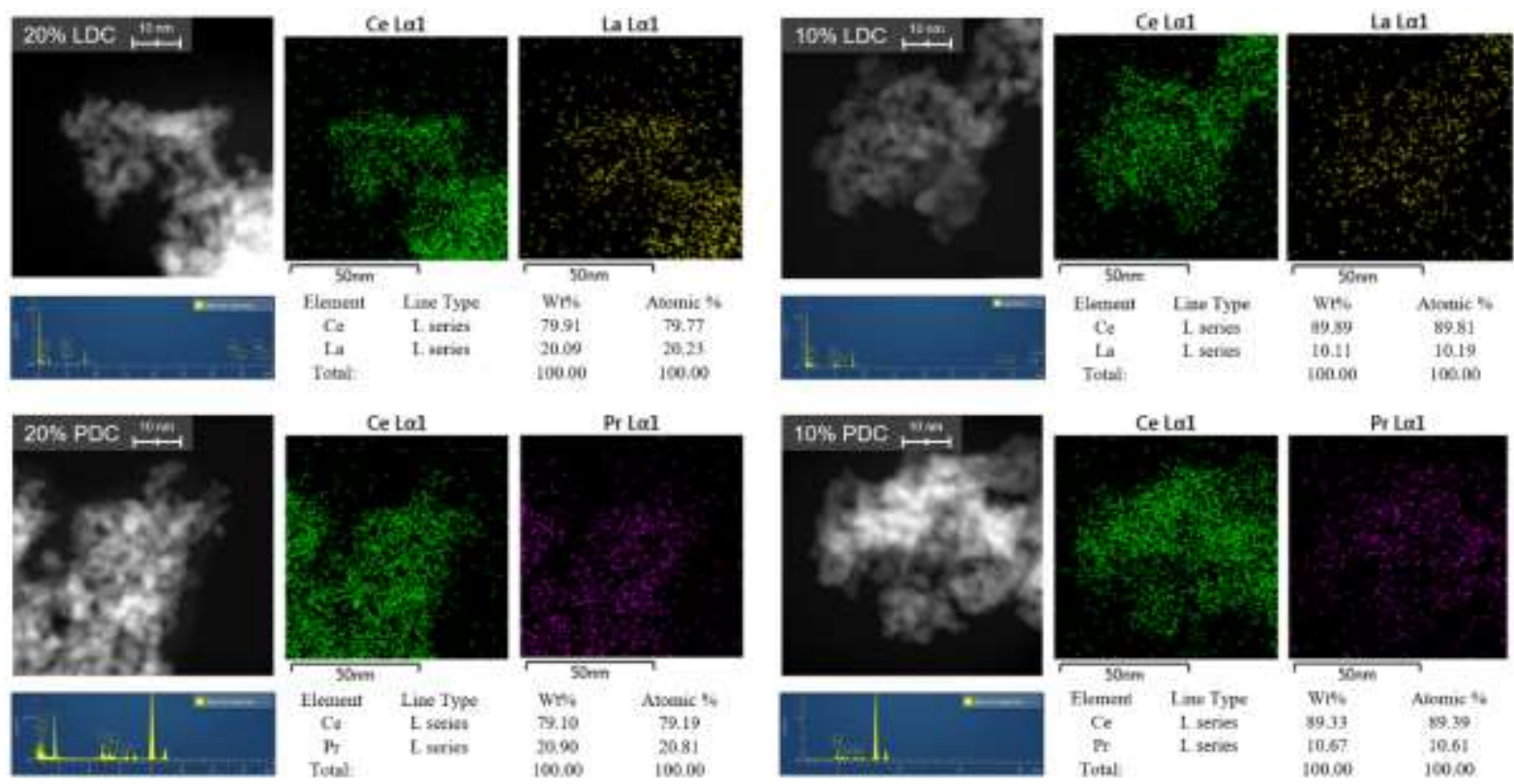

Total:
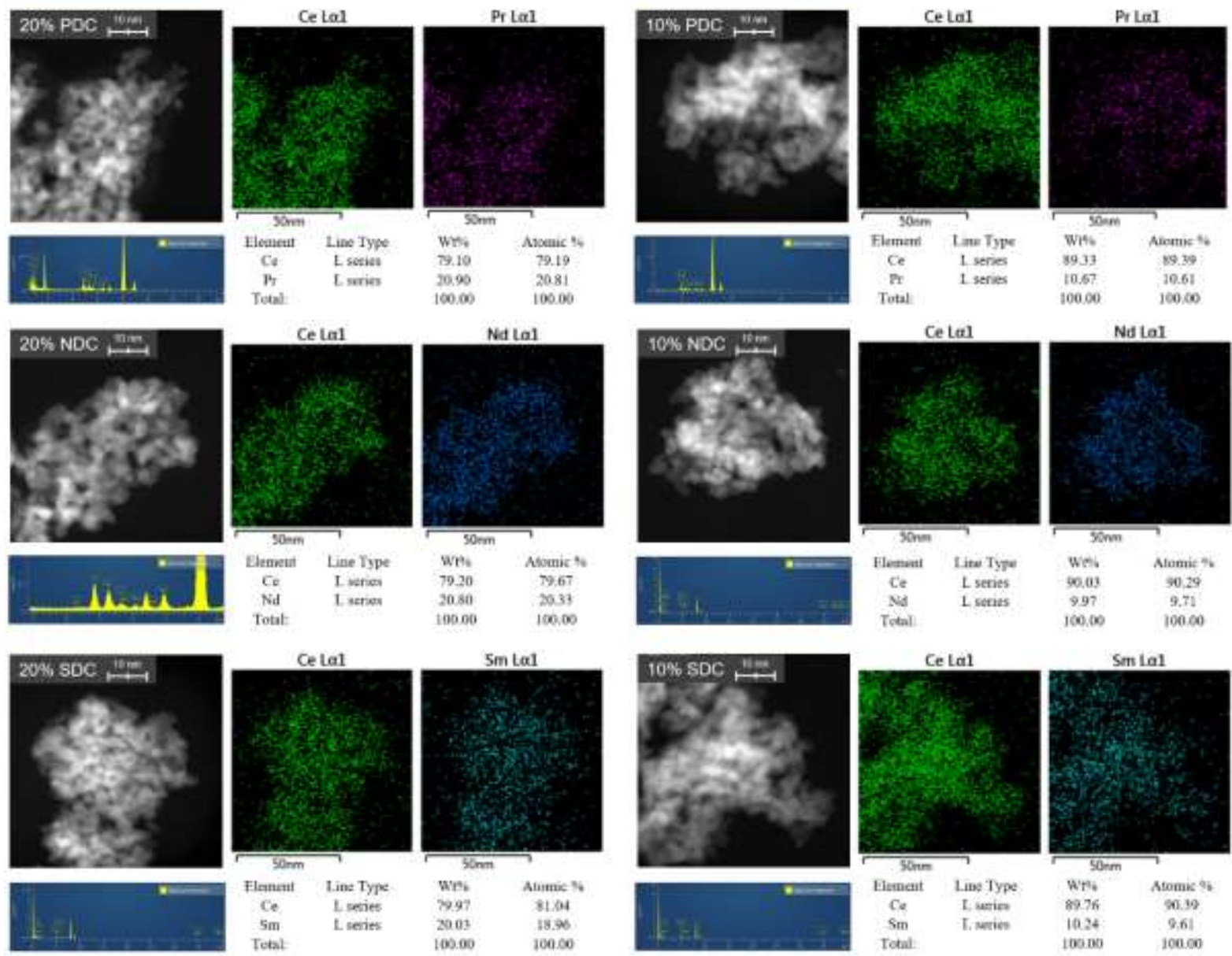

Eismat Lise Type
Ce

(x)

Total tos 10000

Figure S3: TEM-EDS mapping and distribution analysis of well-synthesized composites at the same condition $(\mathrm{S}-\mathrm{REC}) ; \mathrm{Ce}_{0 .} \mathrm{RE}_{0.1} \mathrm{O}_{2}(\mathrm{RE}=10 \%)$ and $\mathrm{Ce}_{0.8} \mathrm{RE}_{0.2} \mathrm{O}_{2}(\mathrm{RE}=20 \%)$ nanoparticles. 


\begin{tabular}{ccc}
\hline Sample & $\mathrm{Ce}$ & $\mathrm{RE}$ \\
\hline $20 \% \mathrm{LDC}$ & $\mathrm{Ce}_{0.799}$ & $\mathrm{La}_{0.201}$ \\
$10 \% \mathrm{LDC}$ & $\mathrm{Ce}_{0.899}$ & $\mathrm{La}_{0.101}$ \\
$20 \% \mathrm{PDC}$ & $\mathrm{Ce}_{0.801}$ & $\mathrm{Pr}_{0.199}$ \\
$10 \% \mathrm{PDC}$ & $\mathrm{Ce}_{0.898}$ & $\mathrm{Pr}_{0.102}$ \\
$20 \% \mathrm{NDC}$ & $\mathrm{Ce}_{0.802}$ & $\mathrm{Nd}_{0.198}$ \\
$10 \% \mathrm{NDC}$ & $\mathrm{Ce}_{0.901}$ & $\mathrm{Nd}_{0.099}$ \\
$20 \% \mathrm{SDC}$ & $\mathrm{Ce}_{0.797}$ & $\mathrm{Sm}_{0.203}$ \\
$10 \% \mathrm{SDC}$ & $\mathrm{Ce}_{0.898}$ & $\mathrm{Sm}_{0.102}$ \\
\hline
\end{tabular}

Table S2: ICP-AES analysis of well-synthesized composites at the same condition (S-REC); $\mathrm{Ce}_{0.9} \mathrm{RE}_{0.1} \mathrm{O}_{2}$ and $\mathrm{Ce}_{0.8} \mathrm{RE}_{0.2} \mathrm{O}_{2}$ nanoparticles. The samples were analyzed three times and averaged.
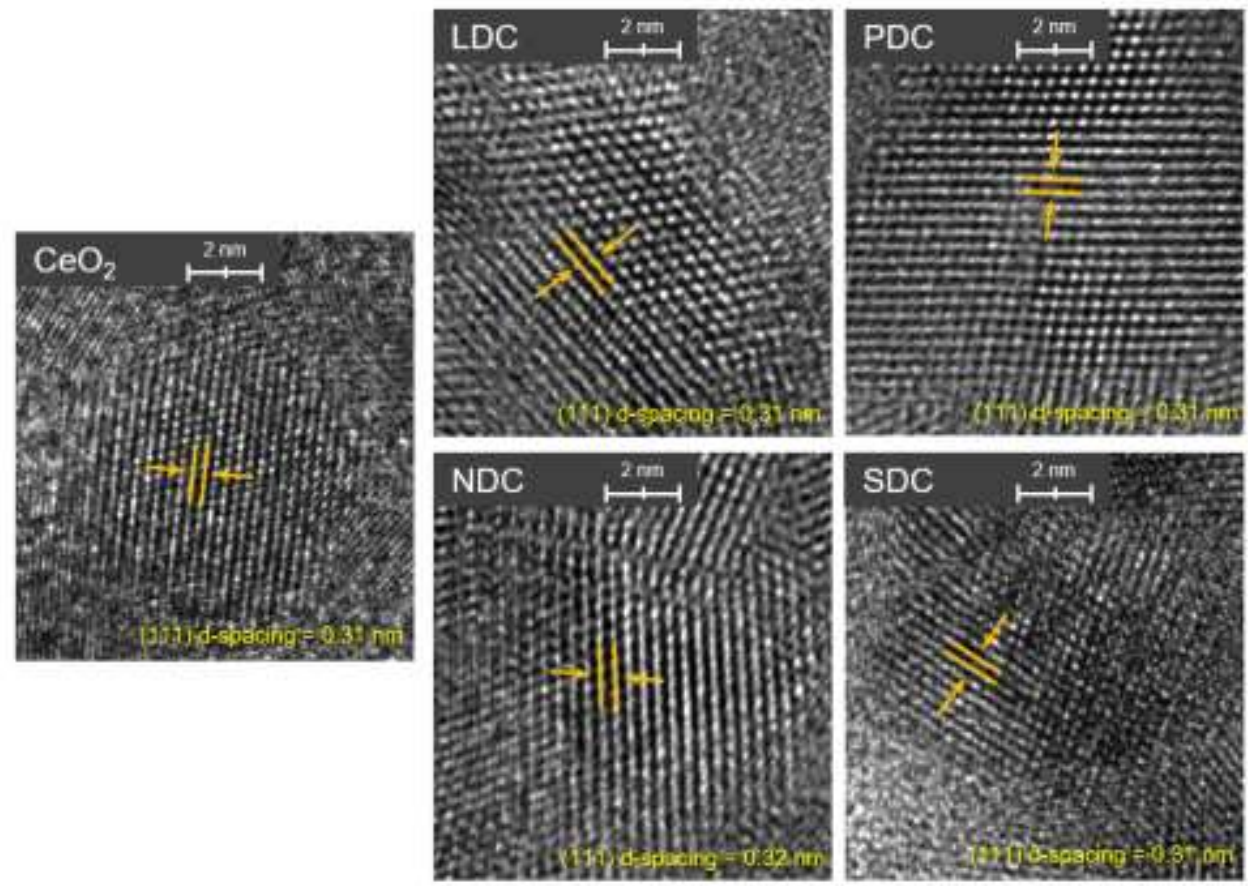

Figure S4: HRTEM images of well-synthesized composites at the same condition (S-REC); pure $\mathrm{CeO}_{2}$ and $\mathrm{Ce}_{0.8} \mathrm{RE}_{0.2} \mathrm{O}_{2}(\mathrm{RE}=20 \%)$ nanoparticles. 
(a)

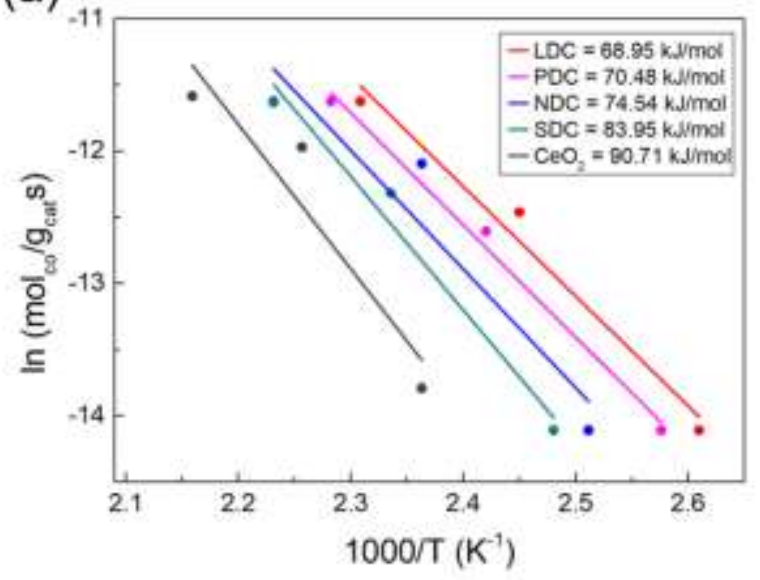

(b)

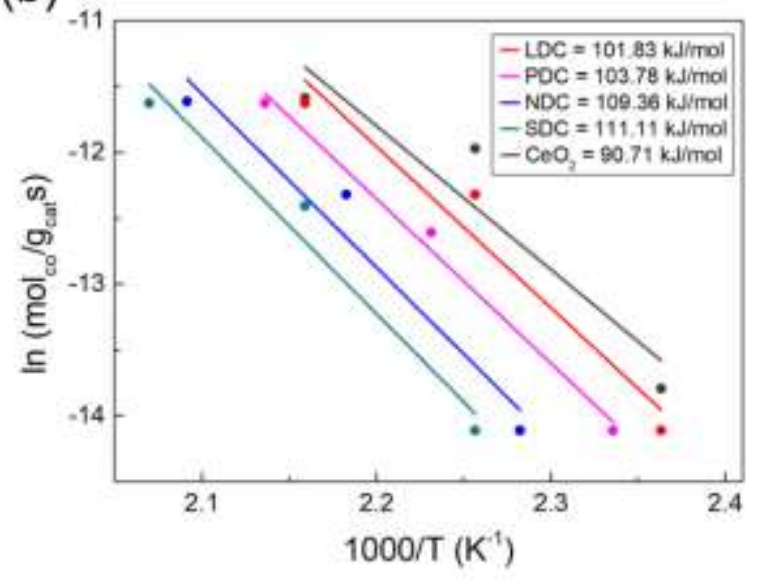

Figure S5: Arrhenius plots for $\mathrm{CO}$ oxidation of $\mathrm{Ce}_{0.8} \mathrm{RE}_{0.2} \mathrm{O}_{2}(\mathrm{RE}=20 \%)$ composites; (a) SREC nanoparticles and (b) C-REC nanoparticles. 
(a)

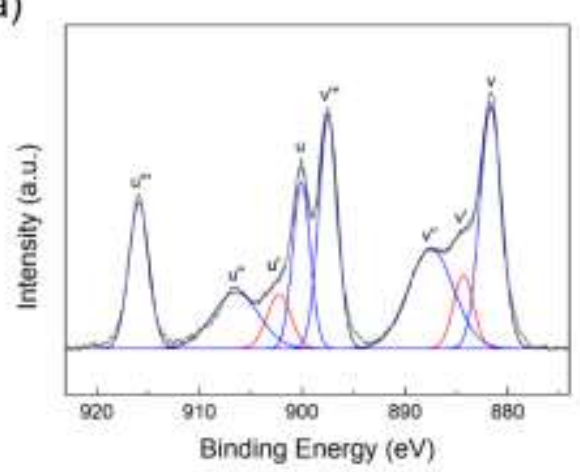

(c)

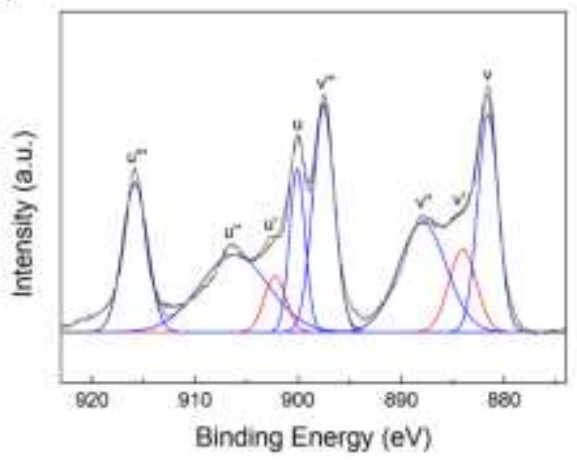

(e)

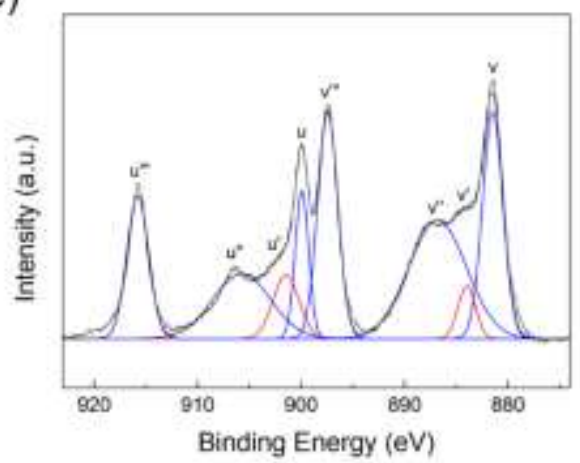

(g)

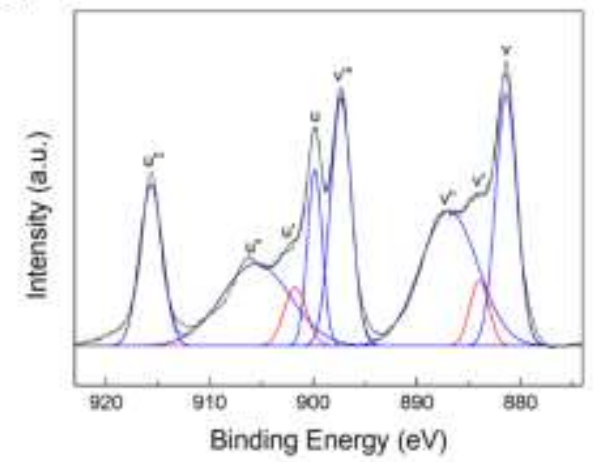

(b)

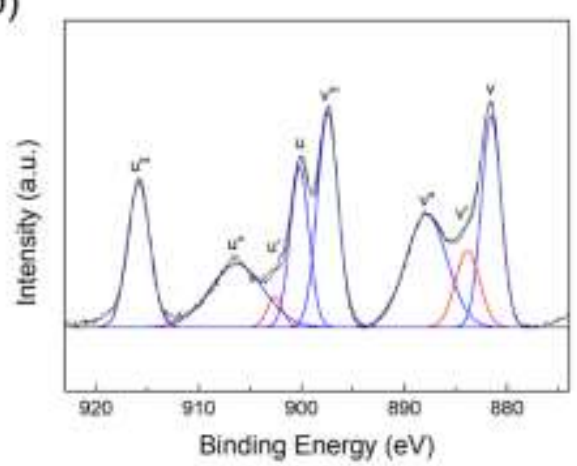

(d)

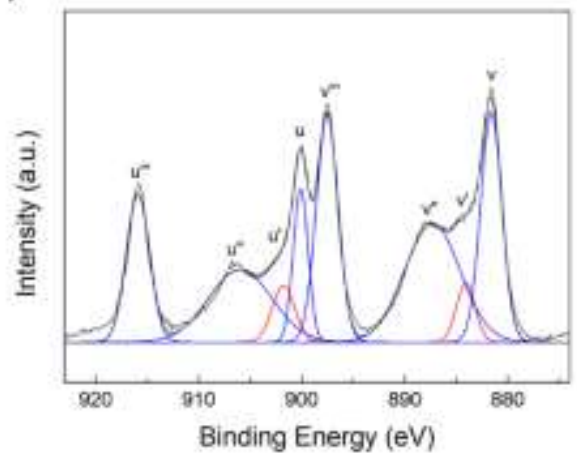

(f)

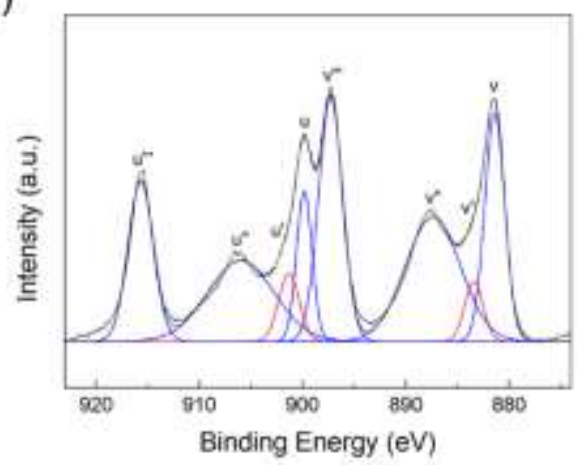

(h)

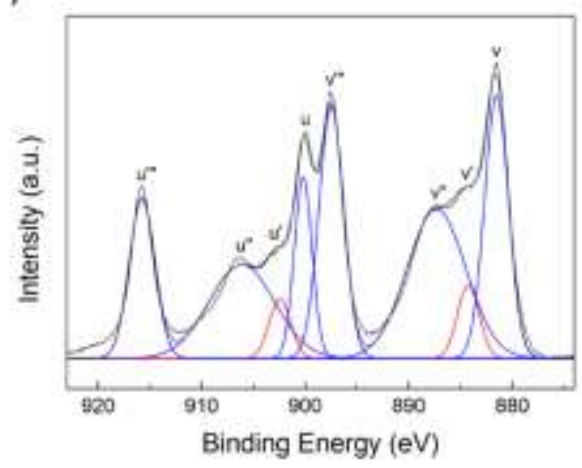

Figure S6: XPS spectra of (a) (d) 20\% S-REC nanoparticles; (a) LDC, (b) PDC, (c) NDC, (d) SDC and (e) (h) 20\% C-REC nanoparticles; (e) LDC, (f) PDC, (g) NDC, (h) SDC nanoparticles. The peaks of (v'"), (v"), (v), (u'"), (u"), and (u) were assigned to $\mathrm{Ce}^{4+}$ species while the peaks of $\left(v^{\prime}\right)$ and $\left(u^{\prime}\right)$ were assigned to $\mathrm{Ce}^{3+}$ species. 


\section{Computational information}

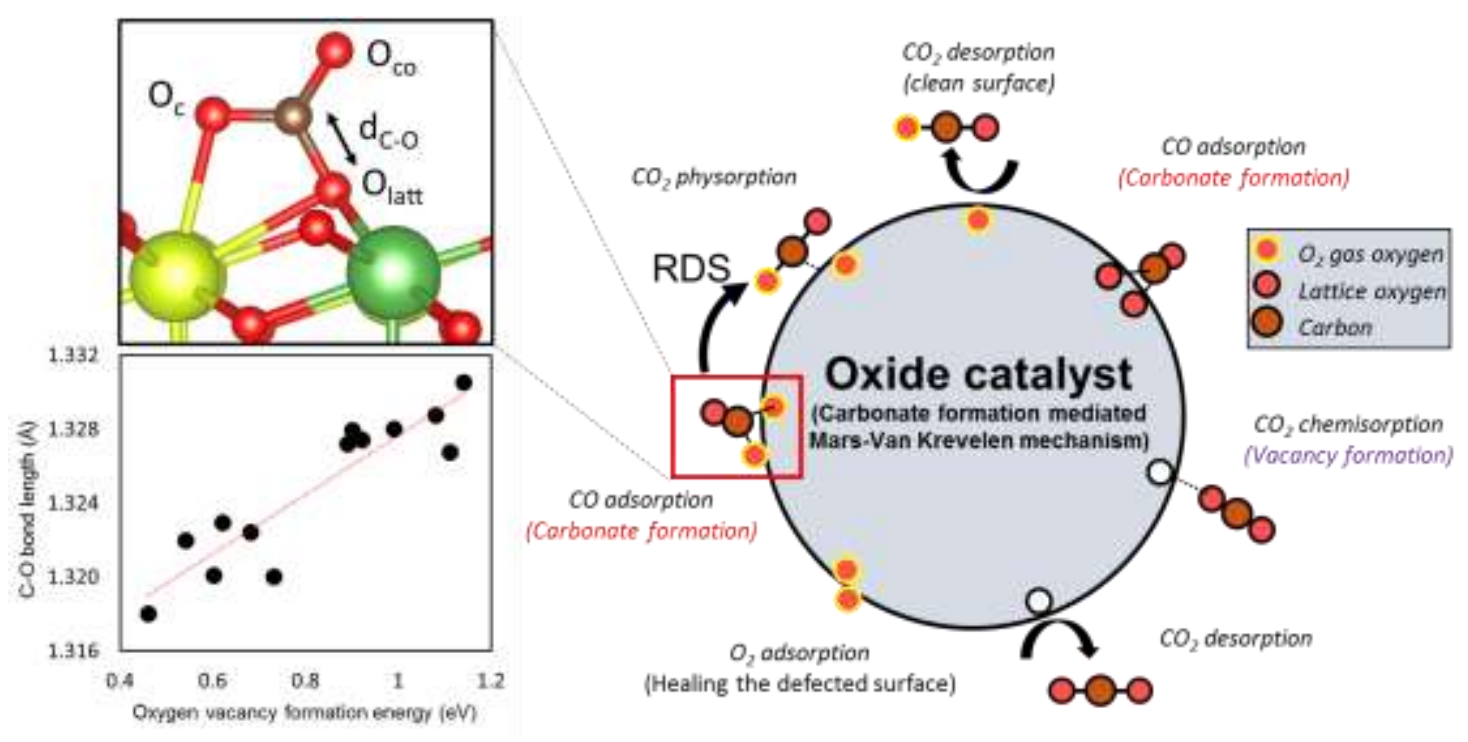

Figure S7: Relationship of bond length between $\mathrm{C}$ atom in carbonate species and lattice oxygen $\left(\mathrm{O}_{\text {latt }}\right)$ with oxygen vacancy formation energy of rare earth metal doped $\mathrm{CeO}_{2}(111)$ at ratedetermining step of CO oxidation via Mars-van Krevelen (MvK) mechanism. Left side of figures are reprinted from Kim et al. with permission. ${ }^{1}$ Copyright 2017, Elsevier. Right side of a figure is reprinted from Kim et al. with permission. ${ }^{2}$ Copyright 2017, American Chemical Society. 

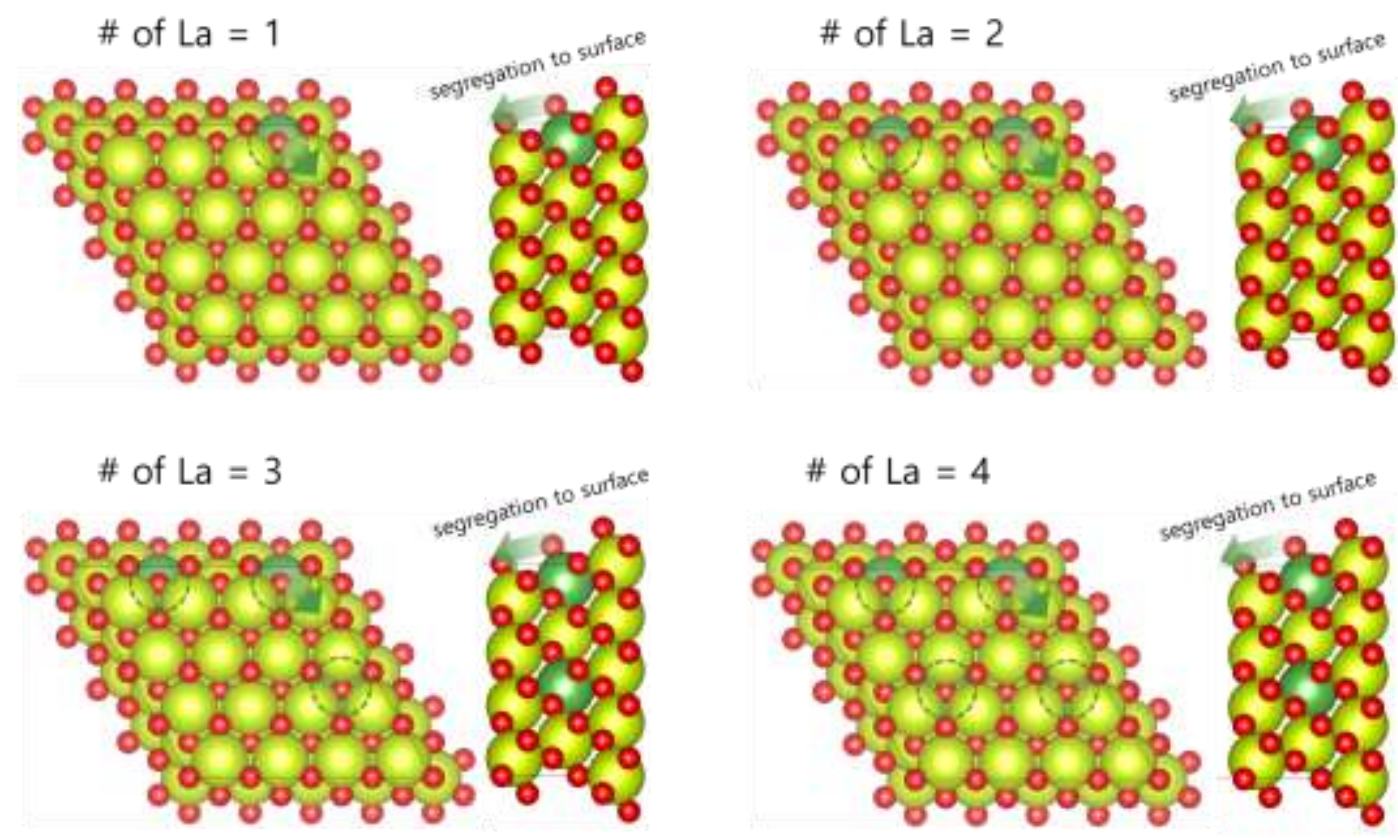

Figure S8. Atomic configurations of La-doped $\mathrm{CeO}_{2}(111)$ (LDC) slab models as a function of the number of La dopants, which were employed to calculate the segregation energies $\left(E_{\mathrm{seg}}\right)$ of LDCs at different concentrations.

$2 \times 2 \times 2 \mathrm{CeO}_{2}$ supercell doped with two RE dopants

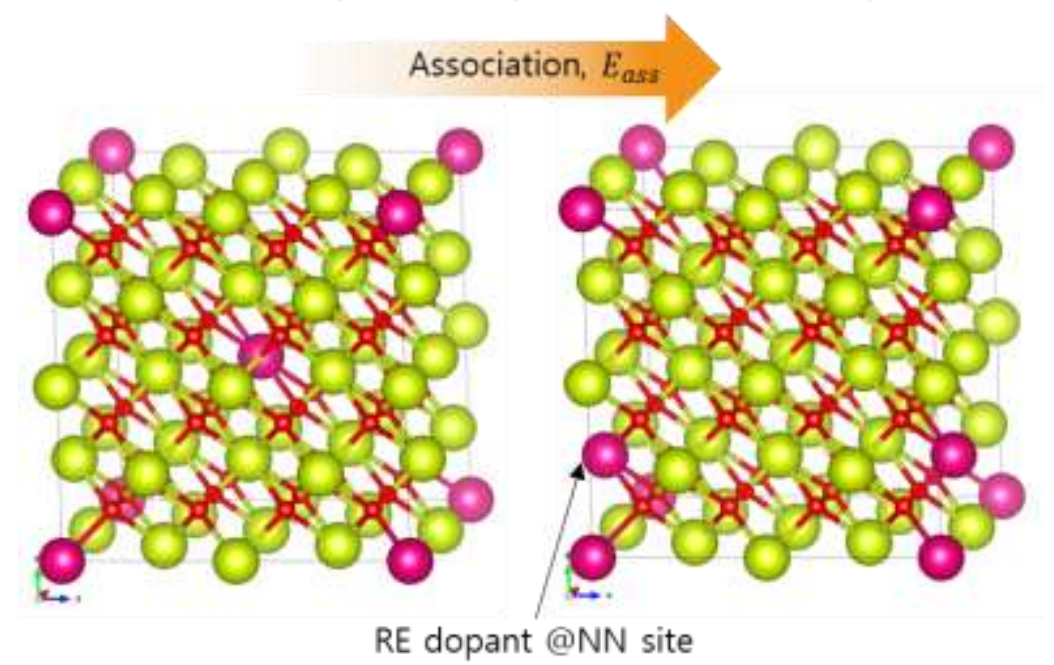

Figure S9. Atomic configurations of RE-doped $\mathrm{CeO}_{2}$ (REC) bulk models which were employed to calculate the association energies $\left(E_{\text {ass }}\right)$ of RECs $(\mathrm{RE}=\mathrm{La}, \mathrm{Pr}, \mathrm{Nd}, \mathrm{Sm})$. 


\section{References}

(1) Kim, K.; Yoo, J. D.; Lee, S.; Bae, M.; Bae, J.; Jung, W.; Han, J. W. ACS Appl. Mater. Inter. 2017, 9 (18), 15449-15458.

(2) Kim, K.; Han, J. W. Catal. Today 2017, 293-294, 82-88. 